\title{
THE POLITICS OF CONTRACTING OUT: EVIDENCE FROM A REGRESSION DISCONTINUITY DESIGN
}

\author{
JOSÉ M. ALONSO \\ University of Cantabria \\ jmanuel.alonsoalonso@unican.es \\ RHYS ANDREWS \\ Cardiff University
}

\begin{abstract}
We investigate contracting choices in English local governments using a Regression Discontinuity Design (RDD) that captures "near experimental" changes in political control at $50 \%$ of the seats gained in local elections. Our estimates reveal that local governments with small left-wing majorities prefer in-house to private sector social services provision.
\end{abstract}

\section{INTRODUCTION}

The decision about whether to provide public services "in-house" or to contract with a private firm has long been recognized to be a critical issue in the theory and practice of public administration (Prager, 1994). In addition to technical considerations that shape "make or buy" decisions, government contracting entails a political dimension (Brown et al., 2006), with rightwing political parties thought to prefer to contract for services with private firms, and left-wing parties favouring "in-house" state-led services (Bel and Fageda, 2007).

To date, scholarship dealing with the politics of government contracting has largely been cross-sectional in design and has rarely utilized the kinds of quasi-experimental approaches that can underpin a robust and credible identification strategy. While this research has undoubtedly shed much valuable light on the nature of government contracting, there is a pressing need for empirical studies that employ research approaches that can more reliably approximate causal effects. One such approach is the Regression Discontinuity Design (RDD).

Defined as "a quasi-experimental design with the defining characteristic that the probability of receiving treatment changes discontinuously as a function of one or more underlying variables" (Hahn et al., 2001, p.201), RDDs are widely used in policy evaluation studies (e.g. Cattaneo et al., 2017; Kogan et al., 2016), and have great potential for research in public administration (Dague and Lahey, forthcoming). Importantly, RDDs are highly applicable in government settings characterized by strong bipartisan politics, because the impact of changes in political control that occur near the $50 \%$ majoritarian threshold occur almost randomly and can therefore be regarded as "near experimental" (Pettersson-Lidbom, 2008). Drawing on the citizen-candidate theory of political competition, we use a RDD to analyse the relationship between left-wing political control and the institutional arrangements for the placement of children looked after by English local governments between 2009 and 2016.

Local governments in England have a statutory duty to provide care for children who have been placed under a care order by a family court. If they determine that a child should be placed in a children's home, governments are free to contract with private and non-profit social services providers, as well as utilize their own "in-house" services. To analyse the potential for 
political ideology to influence those contracting decisions, we apply a RDD that utilizes the percentage of local government seats held by the Labour Party (the main left-wing political party in the UK) as the running variable. Local governments having $50 \%$ or more seats held by Labour are controlled by the party, and our analysis therefore focuses on governments that are just above and below this treatment threshold, as political control in these cases can be assumed to be close to randomly assigned. We first evaluate the impact of Labour party control on contracting by analysing the proportions of looked after children in the care of each local government that are placed in private care homes. We then repeat our RDD approach for the proportions of looked after children who are placed in homes managed by the local governments themselves.

\section{IDEOLOGICAL INFLUENCES ON CONTRACTING OUT}

Government contracting is regarded as an important means to keep costs down and improve the responsiveness of public services in countries across the globe (Bel and Warner 2008). Efficiency improvements may be achieved through contracting due to the introduction of competition, particularly via competitive tendering processes which select the most appropriate (often the cheapest) supplier for the job at hand (Domberger and Jensen, 1997). At the same time, the strategic management literature indicates that private firms have a distinctive sectoral advantage in terms of their innovative capabilities, financial capacity and knowledge of new technologies (Goggins and Rochlin, 2000), and it is therefore only by working closely with business that government can hope to maximize the creation of public value (Quélin et al., 2017).

Besides the economic and strategic drivers behind government contracting, noneconomic factors, such as policymakers' ideology and citizens' preferences about the role of government, have long been considered important influences on contracting behaviour (see, for example, Bel and Fageda, 2007, 2009). Within the political economy literature, the citizencandidate model emphasizes that the ideological commitments of a ruling political party are an important influence on a government's policy choices (Besley and Coate, 1997). In theory, leftwing parties are considered less likely to adopt outsourcing decisions due to their pro-state orientation, while right majorities have been linked with higher levels of outsourcing because of their pro-business stance. Indeed, governments led by left-wing parties are thought to be antagonistic towards market-based alternatives to the state, and, therefore, assumed to prefer the extension rather than the reduction of state ownership of public services. By contrast, governments led by right-wing parties are linked with reforms to the public sector intended to weaken the grip of the state over public services by opening them up to competitive tendering by private firms (Osborne and Slivinski, 1996).

While the arguments of the citizen-candidate model are supported by some empirical studies of contracting out by local governments (e.g. Sundell and Lapuente 2012; Zafra-Gómez et al., 2016), to date, the bulk of the empirical literature still reports that political ideology does not seem to influence contracting out decisions (see, e.g., Alonso et al., 2016; Brudney et al., 2005; Fernandez et al., 2008; González-Gómez et al., 2011, Hefetz et al., 2012, Pallesen, 2004; Wassenaar et al., 2013). One of the main drawbacks of the existing empirical studies evaluating the influence of political ideology on contracting out is the lack of a robust and credible identification strategy (a notable exception is Elinder and Jordahl, 2013, who employ a differences-in-differences style analysis). Most previous research on the determinants of government contracting relies upon cross-sectional (e.g. Alonso et al., 2016; Fernandez et al., 2008) or pooled longitudinal data (e.g. Gonzalez-Gomez et al., 2011; Petersen et al., 2015). 
While these approaches have provided scholars of government contracting with valuable information on the relationship between ideology and contracting behaviour, they do not provide accurate and reliable estimates of the direction of that relationship, meaning that the findings from much of the extant literature should be treated with great caution. Due to the largely bipartisan nature of local politics in the major local governments in England, we are able to employ a RDD by treating governments with left-wing majorities that are just above the $50 \%$ threshold needed for a change in political control as being randomly assigned.

\section{DATA AND METHODS}

To estimate the potential effect of political ideology on the contracting out of social services, we collected data from the full population of 150 English single and upper tier local governments for the period 2009 to 2016. These are elected multi-purpose bodies, with a Westminster-style cabinet system of political management made up of senior members of the ruling political party who implement national policy frameworks on the advice of professional local government managers. Strategic commissioning decisions are made by service directors.

We investigate the contracting out of services for children placed in care by English local governments. For the at-risk children taken into care, local governments are responsible for making sure that: an appropriate standard of care is provided; suitable people are employed to look after children; proper training and support is provided to carers; and that a child's views, and those of their family, about care arrangements are taken into account (HM Government, 2018). In the current context of fiscal stress (National Audit Office, 2018), a mixed economy of service delivery has emerged for children's social services in England, with local governments purchasing core as well as specialist services from private firms to meet their statutory responsibilities (Jones, 2018).

Our analysis draws on publicly available information on the providers of placements for looked after children that was collected and published by the UK's Department of Education (https://www.gov.uk/government/collections/statistics-looked-after-children). In particular, we utilize measures of children looked after by type of placement provider, specifically, private providers or "in-house" local government provision. We estimate separate models for the percentage of children in care looked after by private providers $(31.6 \%$ on average), and for the percentage looked after by the local government in-house $(57.5 \%$ on average).

\section{Empirical strategy}

Our identification strategy draws on a distinctive characteristic of the UK's local government electoral system, which is that party control changes discontinuously at $50 \%$ of the number of council seats, giving us the opportunity to implement a RDD. This empirical approach should allow us to address endogeneity biases that might arise if party control is correlated with unobserved factors influencing contracting out. Briefly, RDDs exploit the availability of precise knowledge about "treatment" eligibility criteria relating to whether an observed variable (also called the running variable) falls above or below a certain threshold or cut-off point (Angrist and Pischke, 2008; Lee and Lemieux, 2010). Assuming that the relationship between the running variable and potential confounders varies smoothly at the threshold, the effect of a "treatment" can be approximated by comparing units just below and above the threshold. 
The English local government context is particularly suitable for implementing a RDD approach. Political control of local governments in England is almost entirely held by nationallevel political parties and there is a clear bipartisan division between the pro-state preferences of the main left-wing party (Labour) and parties with pronounced pro-market preferences, such as the right-wing Conservative Party and the Liberal Democrats. Hence, in this paper we estimate the following local linear polynomial RDD approach:

$$
\log \left(y_{i t}\right)=\alpha+\beta T_{i t}+\tau\left(X_{i t}-\bar{x}\right)+\gamma T_{i t}\left(X_{i t}-\bar{x}\right)+\varepsilon_{i t}
$$

where $y_{i t}$ refers to each of our two dependent variables, i.e. the percentage of children looked after by a private provider (contracting out) or the local government itself (in-house provision). The estimate of $\beta$ is our coefficient of interest, which approximates the effect of ideology on the choice of children's social care provider. Local governments are assigned to the treatment status, i.e. Labour Party control, if the running variable $\left(X_{i t}\right)$ is equal or greater than the cut-off point or threshold. In this analysis, the percentage of the total council seats held by the Labour Party is the assignment variable, and the treatment threshold is at $50 \%$ of the number of council seats $(\bar{x}=50)$, hence $T_{i t}=1\left(X_{i t} \geq \bar{x}\right)$. To estimate the RDD proposed in Eq. (1), we use a nonparametric local polynomial approach with a triangular kernel, optimal bandwidth selection and robust confidence intervals (see Calonico et al. 2014). We first restrict the sample to local areas within a data-driven optimal bandwidth, and then estimate a weighted least-squares regression with a triangular kernel weighting function. Tests assessing the continuity of the running variable around the threshold by means of a local polynomial distribution regression approach indicate that there is no evidence of discontinuity around the threshold ( $p$-value equal to 0.3606).

\section{RESULTS}

Figure 1 depicts RD plots for private provision of placements for looked after children (Fig. 1A) and in-house provision of placements (Fig. 1B). These plots suggest a potential effect of left-wing ideology on the choice of children's social care services provider; the RD plot for private provision shows a clear downward discontinuity just at the right side of the threshold (or cut-off) vertical line, while the RD plot for in-house provision exhibits an upward discontinuity.

FIGURE 1 ABOUT HERE

Our RDD estimates using robust 95\% confidence intervals for the local linear polynomial approach described in Eq. (1). affirm that Labour Party control has an effect on whether English local governments contract with private providers to deliver children social care services. The RDD coefficient based on mean square error (MSE)-optimal bandwidths ( $\beta=-0.38 ; 95 \% \mathrm{CI}[-$ $0.75,-0.12]$ ) indicates that left-wing local governments appear to be about $38 \%$ less likely to use private contractors to accommodate looked after children, when compared to local governments with any other form of political control. When using coverage error rate (CER) optimal bandwidths, the RDD estimate points to a similar effect $(\beta=-0.40 ; 95 \%$ CI $[-0.78,-0.07])$.

Likewise, when looking at the political control effect on the share of children looked after in-house, our results suggest that Labour-controlled local governments seem to rely more on 
their own provision of social care services than governments exhibiting other forms of political control. Based on MSE optimal bandwidths, the RD estimate is 0.17 (95\% CI [0.08, 0.30]), while when using CER optimal bandwidths, the RD estimate for in-house provision is again very similar $(0.19 ; 95 \%$ CI $[0.07,0.33])$, giving us further confidence in the robustness of our findings.

To address the possibility that relatively low number of observations at each side of the threshold bias our RDD estimates, we add a set of control variables to our models. The rate of socio-economic deprivation and proportion of different ethnic sub/groups within the local population account for vulnerable citizens' preference for government provision of public services (Brudney et al. 2005). The total population and population density for each local government control for economies of scale and scope (see Bel and Fageda 2009).

The point estimates are slightly smaller following the inclusion of control variables in our models, but the results are virtually identical. Furthermore, non-parametric local linear estimates using Epanechnikov kernel functions, and Uniform kernel functions also suggest that Labour controlled local governments are likely to have a lower share of children looked after by private providers and a higher share of children looked after by the local government itself.

\section{DISCUSSION}

Our RDD estimates suggest political ideology may play a critical role in shaping contracting out decisions in children's social services in England: left-wing (Labour Party)controlled local governments are less likely to procure services for looked after children from private providers, and more likely to utilize their own in-house services to place children in care. These findings provide credible statistical evidence that contracting out decisions reflect the ideological imperatives of ruling political parties, because unlike most prior studies we have been able to illustrate these ideological effects using a quasi-experimental RDD research design. In addition, our analysis reveals that political ideology may have an important influence on contracting decisions within the field of social services in an Anglo-Saxon country (i.e. the UK), which has a well-developed and thriving outsourcing industry (Julius, 2008). Prior research on contracting for social services has largely concentrated on elderly care and children's day care in social democratic countries, where the state has a stronger role in provision (e.g. Petersen et al., 2015).

Although we offer a rare quasi-experimental test of the effect of ideology on contracting out decisions, datasets incorporating information on annual expenditure on the specific services provided by contractors, as well as those managed in-house, would enable the nature of contracting out in children's social services to be investigated in more depth. Whether left or right-wing governments are better at managing private (and non-profit) contractors is beyond the scope of this study, but is another issue that should certainly form the backdrop for further research into ideological effects on government contracting. Furthermore, in-depth case studies involving interviews with key actors involved in making local social services contracting decisions would add greatly to our understanding of the political management strategies that lie behind this complex issue (Lindholst et al., forthcoming).

To conclude, we hope that our study provides a foundation for further empirical tests of the politics of privatization in other settings, and for other services than those provided for the children taken into care by local governments. 


\section{REFERENCES AVAILABLE FROM THE AUTHORS}

\section{FIGURE 1}

\section{Estimated impact of political control on contracting out}

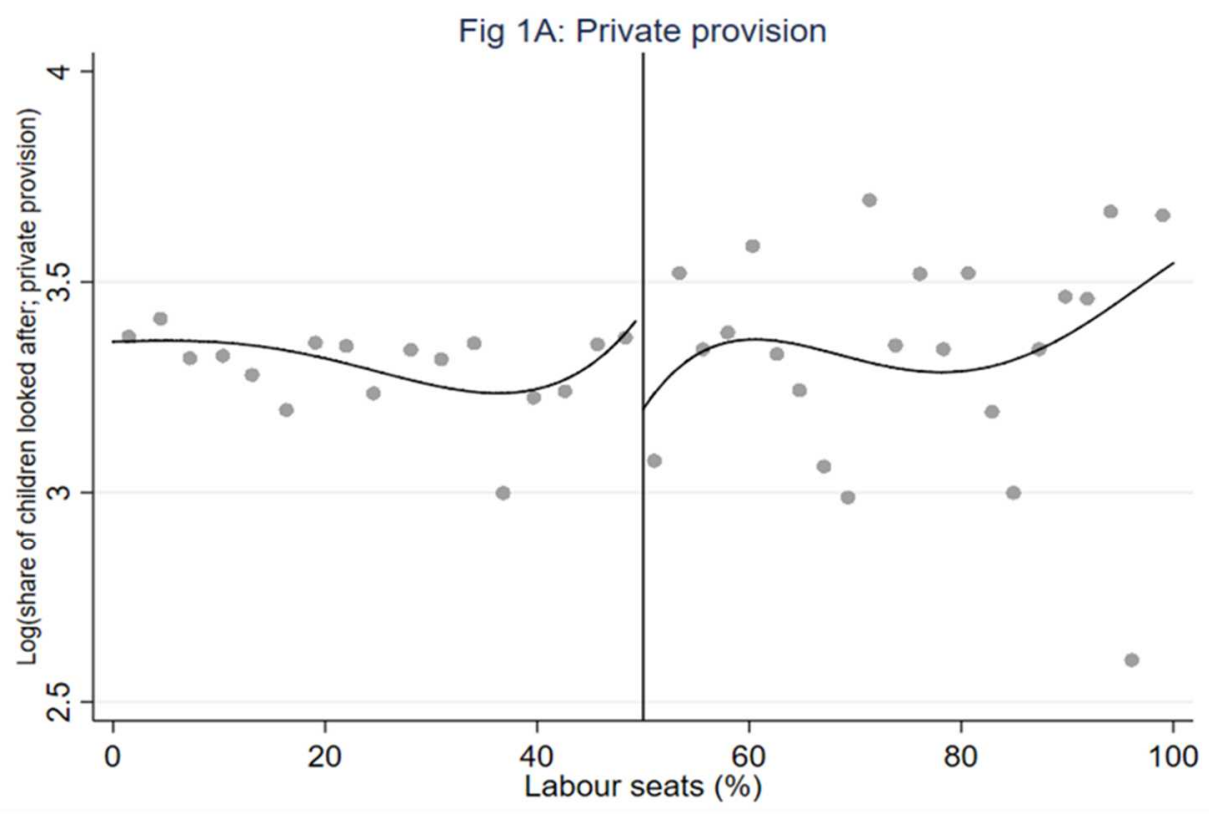

Fig 1B: Inhouse provision

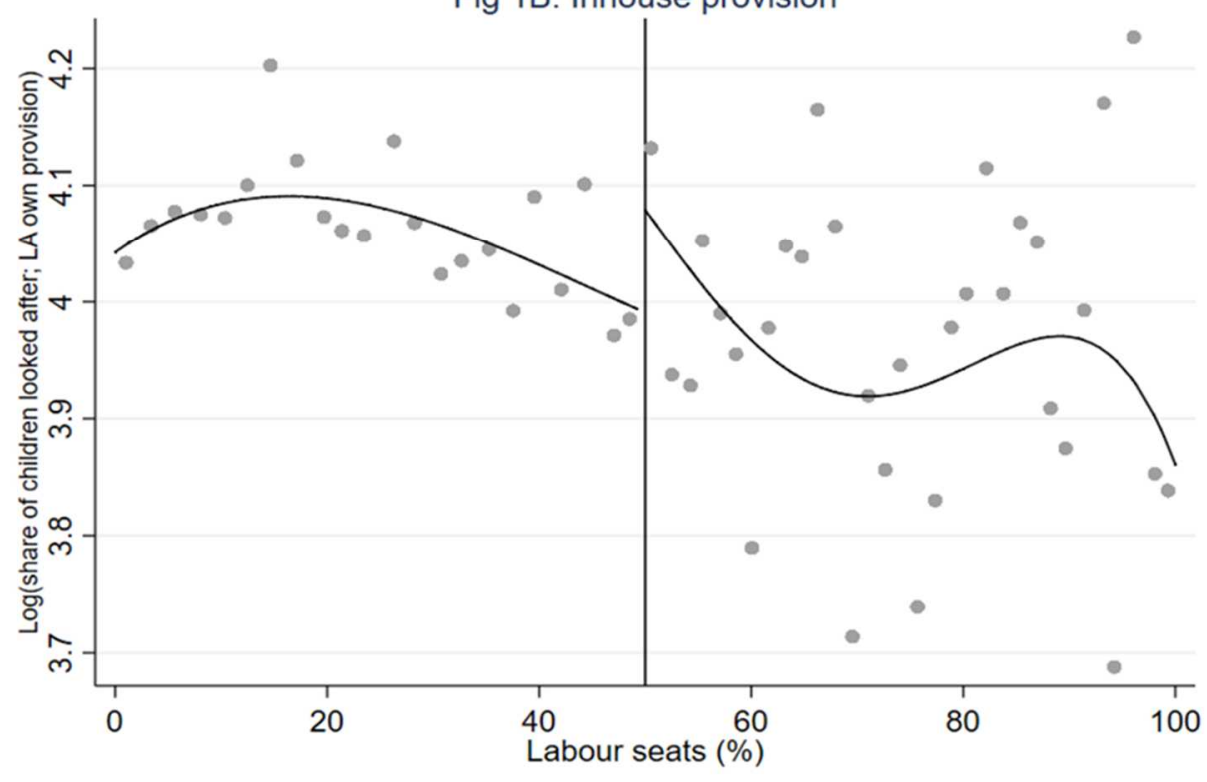

Notes: Figure shows standard RDD plots. Observations are averaged within bins using the mimicking variance evenly-spaced method described in Calonico et al. (2015). Each plot includes $4^{\text {th }}$ order global polynomial fits represented by the solid lines. Plots are constructed using the software developed by Calonico et al., (2017). 